\title{
Circulating antigens in mice infected with Mycobacterium tuberculosis and in patients with tuberculosis
}

\author{
Bibiana P. Ruiz-Sánchez ${ }^{1,2}$, Alejandro Francisco-Cruz²,3, Sergio Miguel-Hernández¹, \\ Jessica Castañeda-Casimiro ${ }^{1}$, Alejandro Hernández-Solis ${ }^{4}$, Raúl Cicero-Sabido ${ }^{5}$, \\ Rommel Chacón-Salinas ${ }^{1,6}$, Jeanet Serafín-López ${ }^{1}$, Dulce Mata-Espinosa ${ }^{3}$, Jorge Barrios-Payán ${ }^{3}$, \\ Rogelio Hernández-Pando ${ }^{3}$, Sergio Estrada-Parra ${ }^{1}$, Isabel Wong-Baeza ${ }^{1}$, and Iris Estrada-García ${ }^{1 *}$ \\ ${ }^{1}$ Department of Immunology, Escuela Nacional de Ciencias Biológicas, Instituto Politécnico Nacional; ${ }^{2}$ Postgraduate Immunology, Escuela Nacional \\ de Ciencias Biológicas, Instituto Politécnico Nacional; ${ }^{3}$ Experimental Pathology Section, Department of Pathology, Instituto Nacional de Ciencias \\ Médicas y Nutrición Salvador Zubirán; ${ }^{4}$ School of Medicine, Universidad Nacional Autónoma de México; ${ }^{5}$ Neummology Service, Hospital General \\ de México "Dr. Eduardo Liceaga", Secretaría de Salud; "Unit of Bioprocesses Research and Development, Escuela Nacional de Ciencias Biológicas, \\ Instituto Politécnico Nacional. Mexico City, Mexico
}

\begin{abstract}
Background: Tuberculosis (TB), a disease caused by Mycobacterium tuberculosis, is a global public health emergency. No serological method is currently approved for the diagnosis of this infection. Objective: The objective of the study was to identify target antigens applicable to serological diagnostic methods for TB. Materials and methods: Sera of infected mice were analyzed by Western blot to detect $M$. tuberculosis antigens, during the acute and the progressive phases of the infection, and after antibiotic treatment. The $97 \mathrm{kDa}$ antigen was then evaluated in the sera of 19 TB patients with positive baciloscopy and 12 healthy volunteers. Results: Mice infected with M. tuberculosis strain H37Rv had mycobacterial antigens in their sera from day 1 up to day 180 post-infection, including an antigen of $97 \mathrm{kDa}$. These circulating mycobacterial antigens decreased after treatment with isoniazid, rifampicin, and pyrazinamide in mice infected with antibiotic-susceptible M. tuberculosis. A $97 \mathrm{kDa}$ antigen was also present in the sera of mice infected with a virulent Mycobacterium bovis strain, but not in the sera of mice infected with an avirulent strain. The sera of TB patients contained higher concentrations of the $97 \mathrm{kDa}$ antigen than the sera of healthy volunteers. Conclusion: The $97 \mathrm{kDa}$ antigen that we identified in mouse models of mycobacterial infection and in TB patients could be a target for serological diagnostic methods for TB.
\end{abstract}

Key words: Mycobacterial antigens. Western blot. Serological diagnostic test

\section{Introduction}

Tuberculosis (TB), a disease caused by Mycobacterium tuberculosis, is a global health problem 1 . Up to one-third of the global population may be infected with $M$. tuberculosis in an asymptomatic form latent TB infection, and $5-10 \%$ of these people will eventually develop active TB, which is mainly a lung disease. In Mexico, there were 21,184 new cases of active TB in 2016, with a prevalence of 17.3 cases $/ 100,000$ people and a mortality rate of $1.7 / 100,000$ people $^{2}$. The WHO reported a total incidence of 29,000 (22,000-37,000) cases in 2018, with 1900 deaths $^{3}$. Innate and adaptive immune cells control the proliferation and dissemination of $M$. tuberculosis through the formation of granulomas ${ }^{4}$. Antibodies also participate in the control of this infection: B-cell

\section{Correspondence:}

*Iris Estrada-García

E-mail: iestrada5@ hotmail.com
Available online: 21-07-2020

Rev Med Hosp Gen Mex. 2020;83(3):104-112 www.hospitalgeneral.mx 0185-1063/@ 2019 Sociedad Médica del Hospital General de Mexico. Published by Permanyer. This is an open access article under the CC BYNC-ND license (http://creativecommons.org/licenses/by-nc-nd/4.0/). 
deficiency is associated with higher mycobacterial burdens and tissue injury ${ }^{5,6}$ and antibodies against $M$. tuberculosis antigens reduce $M$. tuberculosis dissemination ${ }^{7}$, decrease the lung mycobacterial burden ${ }^{8}$, and increase host survival ${ }^{9}$.

Control of TB incidence would be greatly aided by an effective vaccine, by a short-term drug TB treatment, and by the availability of a sensitive, fast, and inexpensive point-of-care TB diagnostic test, which would allow the immediate initiation of antibiotic therapy ${ }^{10}$. Active pulmonary TB is currently diagnosed by baciloscopy, which has low sensitivity; by mycobacterial culture, which has higher sensitivity but can only be performed in specialized laboratories; and by molecular biology methods, which are highly sensitive and specific, but require expensive equipment and training ${ }^{10}$. Serological diagnostic methods are attractive because they are fast, easy to perform, and do not require sophisticated equipment. Several M. tuberculosis antigens have been suggested as possible serodiagnostic targets; in most cases, the proposed serological diagnostic test identifies antibodies against mycobacterial antigens. However, methods targeting antibodies depend on correct immune activation and specific antibody production after M. tuberculosis infection, while methods directly targeting $M$. tuberculosis antigens are useful as soon as a person is infected ${ }^{11}$. In this study, we used a Western blot method to detect mycobacterial antigens in the sera of mice infected with $M$. tuberculosis and in patients with active pulmonary TB; these antigens could be applied to serological methods for TB diagnosis.

\section{Materials and methods}

\section{M. tuberculosis and Mycobacterium bovis strains}

M. tuberculosis H37Rv (ATCC 27294), a virulent strain susceptible to isoniazid, rifampicin, and pyrazinamide, and M. tuberculosis CIBIN99, a clinical isolate resistant to isoniazid, rifampicin, and pyrazinamide (multidrug-resistant [MDR]), were cultured in $7 \mathrm{H} 9$ medium at $37^{\circ} \mathrm{C}$ (BD Difco, Becton, Dickinson and Company, Franklin Lakes, $\mathrm{NJ}$ ) to logarithmic growth and adjusted to $2.5 \times 10^{5}$ colony-forming unit (CFU) per $100 \mu \mathrm{l}$ of phosphate-buffered saline (PBS). M. bovis 534 , an avirulent strain, and $M$. bovis AN5, a virulent strain, were cultured in $7 \mathrm{H} 9$ medium enriched with glycerol, albumin, catalase, and dextrose at $37^{\circ} \mathrm{C}$ to logarithmic growth and adjusted to $2.5 \times 10^{5} \mathrm{CFU}$ per $100 \mu \mathrm{l}$ of PBS.

\section{Laboratory animals}

Rabbits and BALB/c mice were housed and manipulated according to the Guide for the Care and Use of Laboratory Animals (National Academy of Sciences, 2011). All our protocols for animal care and use were reviewed and approved by the Bioethics Committee of ENCB-IPN (CEI-ENCB 007/2013).

\section{Infection of BALB/c mice with mycobacteria}

Male, 6-8-week-old BALB/c mice were infected by intratracheal administration of $2.5 \times 10^{5} \mathrm{CFU}$ of $\mathrm{M}$. tuberculosis H37Rv, M. tuberculosis CIBIN99, M. bovis 534 , or $M$. bovis AN5, and serum samples were collected on the indicated days post-infection. Sera were filtered through a $0.45 \mu \mathrm{m}$ pore size membrane and stored at $-20^{\circ} \mathrm{C}$. In some experiments, infected mice were treated with isoniazid $(10 \mathrm{mg} / \mathrm{kg})$, rifampicin (10 mg/kg), and pyrazinamide (30 mg/kg); antibiotic treatment was started on day 60 post-infection and was administered daily.

\section{Patient selection criteria}

This study was approved by the Ethics and Research Committee of the General Hospital of Mexico (DIC/07/406/03/007). We obtained serum samples from patients (18 to 60 years old) with a first episode of active pulmonary TB; these patients had not been previously treated for TB. Active pulmonary TB was diagnosed according to the clinical presentation of the disease, the thoracic X-ray image, and the baciloscopy. Patients with pregnancy, recent $(<4$ weeks) major surgery, immunosuppressive treatment, immunodeficiency, HIV infection, cancer, diabetes mellitus, or autoimmune disease were not included in this study. A group of healthy volunteers was also included in this study. All the individuals gave written informed consent to participate in this study, in accordance with the Declaration of Helsinki.

\section{Preparation of M. tuberculosis H37Rv extracts}

M. tuberculosis H37Rv was cultured in Proskauer-Beck-Youmans medium at $37^{\circ} \mathrm{C}$ for 4 weeks. Bacteria were resuspended in saline solution with protease inhibitors (Complete Mini Protease Inhibitor Cocktail, Roche, Mannheim, Germany). To obtain M. tuberculosis total 
extract (MTTE), bacteria were subjected to six lysing cycles (2500 psi each) in a French press (Sim-Aminco, Spectronic Instruments, Rochester, NY). To obtain M. tuberculosis soluble extract (MTSE), the MTTE was centrifuged twice at $9000 \mathrm{~g}$ for $10 \mathrm{~min}$ and $4^{\circ} \mathrm{C}$, and the supernatant was recovered. Protein concentration in the extracts was determined with the Bradford method (BioRad Laboratories, Hercules, CA). The extracts were stored at $-20^{\circ} \mathrm{C}$.

\section{Preparation of a rabbit serum with antibodies against anti-MTTE}

A 2-month-old male rabbit was immunized by subcutaneous injection of $2.5 \mathrm{mg}$ of MTTE, which was mixed 1:2 with incomplete Freund's adjuvant (Sigma-Aldrich, St. Louis, MO). After 2 weeks, another subcutaneous injection of $2.5 \mathrm{mg}$ of MTTE with incomplete Freund's adjuvant was administered and, after 1 more week, the rabbit was anesthetized (ketamine, $100 \mathrm{mg}$ ), bled by intracardiac puncture and euthanized. The blood was collected in a glass tube and allowed to clot for $3 \mathrm{~h}$ at $4^{\circ} \mathrm{C}$. Serum was recovered by centrifugation and stored at $-20^{\circ} \mathrm{C}$. Blood was also collected from a non-immunized rabbit, to use as a specificity control.

\section{Detection of M. tuberculosis antigens in sera by Western blot}

MTTE or MTSE (16 $\mu \mathrm{g} /$ well), filtered mice sera ( $87.5 \mu \mathrm{g} /$ well), or filtered human sera $(87.5 \mu \mathrm{g} /$ well) were mixed with a buffer (Tris-HCl $1 \mathrm{M} \mathrm{pH} 8.4$, sucrose $0.5 \mathrm{M}$, EDTA $0.5 \mathrm{M}$, bromophenol blue $0.03 \%$, DTT $1 \%$, and SDS 10\%), boiled for $5 \mathrm{~min}$, and separated by SDS $3 / 10 \%$ or $3 / 6 \%$ polyacrylamide gel electrophoresis (PAGE). The proteins were then transferred to a polyvinylidene fluoride membrane, which was soaked in PBS with $0.05 \%$ Tween 20 for $20 \mathrm{~min}$ at room temperature, and blocked in PBS with $0.05 \%$ Tween 20 and 1\% skimmed milk for $45 \mathrm{~min}$ at $37^{\circ} \mathrm{C}$. The rabbit serum with antibodies anti-MTTE was diluted 1:5000 in blocking buffer, added to the membranes, and left overnight at $4^{\circ} \mathrm{C}$. The membranes were then washed 10 times with PBS with $0.05 \%$ Tween 20 and 5 times with PBS, and the secondary antibody (horseradish peroxidase-conjugated donkey anti-rabbit immunoglobulin G (lgGs), BioLegend, San Diego, CA) diluted 1:2000 in blocking buffer, was added, and left for $1 \mathrm{~h}$ at 37 . The membranes were revealed with diaminobenzidine and hydrogen peroxide, and photographed in a Multilmage Light
Cabinet with Alphalmager software (Alpha Innotech Corporation, San Leandro, CA). The photographs were analyzed with ImageJ Software 1.8.0 (NIH, Bethesda, $M D$ ), to determine the area under the curve (AUC) of the graph that represents each band. Statistical analyses were performed with Prism 6.0 (GraphPad Software, La Jolla, CA).

To determine the optimal dilution of the rabbit serum with antibodies anti-MTTE, several dilutions were tested (1:2000, 1:3000, 1:5000, 1:10,000, 1:15,000, 1:20,000, and 1:30,000); the 1:5000 dilution was selected because it allows a sharper separation of bands in MTTE.

\section{Results}

$B A L B / c$ mice were infected intratracheally with M. tuberculosis $\mathrm{H} 37 \mathrm{Rv}$; sera were collected on days $1,3,7,14,21$, and 28 post-infection and analyzed by Western blot, with anti-MTTE rabbit serum as the primary antibody. Mycobacterial antigens were detected in the sera of these mice for the $1^{\text {st }}$ day post-infection, with molecular masses of 112, 50, 45, 29-30 (two bands), and $<15 \mathrm{kDa}$ (Fig. 1A). Since the $112 \mathrm{kDa}$ antigen band is located in the top fourth of the $3 / 10 \%$ polyacrylamide gel, we performed $3 / 6 \%$ SDS-PAGE to determine the molecular mass of this antigen with higher accuracy (Fig. 2A); this antigen is hereafter referred to as the $97 \mathrm{kDa}$ antigen. A decrease in antigen concentration on days 14 and 21 post-infection (when granulomas are formed in this mouse model of pulmonary $\mathrm{TB})^{12}$ was noted in some mice (Fig. 1A), but overall, the antigen concentration remained constant up to day 28 post-infection (Fig. 1C). Decreased antigen concentration on days 14 and 21 post-infection could be caused by the capture of $M$. tuberculosis antigens inside granulomas; after day 28 , a predominant Th2 response decreases the integrity of the granuloma $^{12}$ and correlates with increased circulating antigens at this time.

Circulating mycobacterial antigens were also found during progressive mycobacterial infection (days 60 180 post-infection) and, on day 120 , in addition to the antigens of the molecular masses indicated above, a $22 \mathrm{kDa}$ antigen was also present in the sera (Fig. 1B and $D$ ). There were no significant differences in the antigens detected in unfiltered sera or in sera filtered through a $0.45 \mu \mathrm{m}$ pore size membrane, so the detected antigens were not part of whole circulating mycobacteria (data not shown). No antigens were detected when the Western blot was performed with the serum of a non-immunized rabbit as the primary 


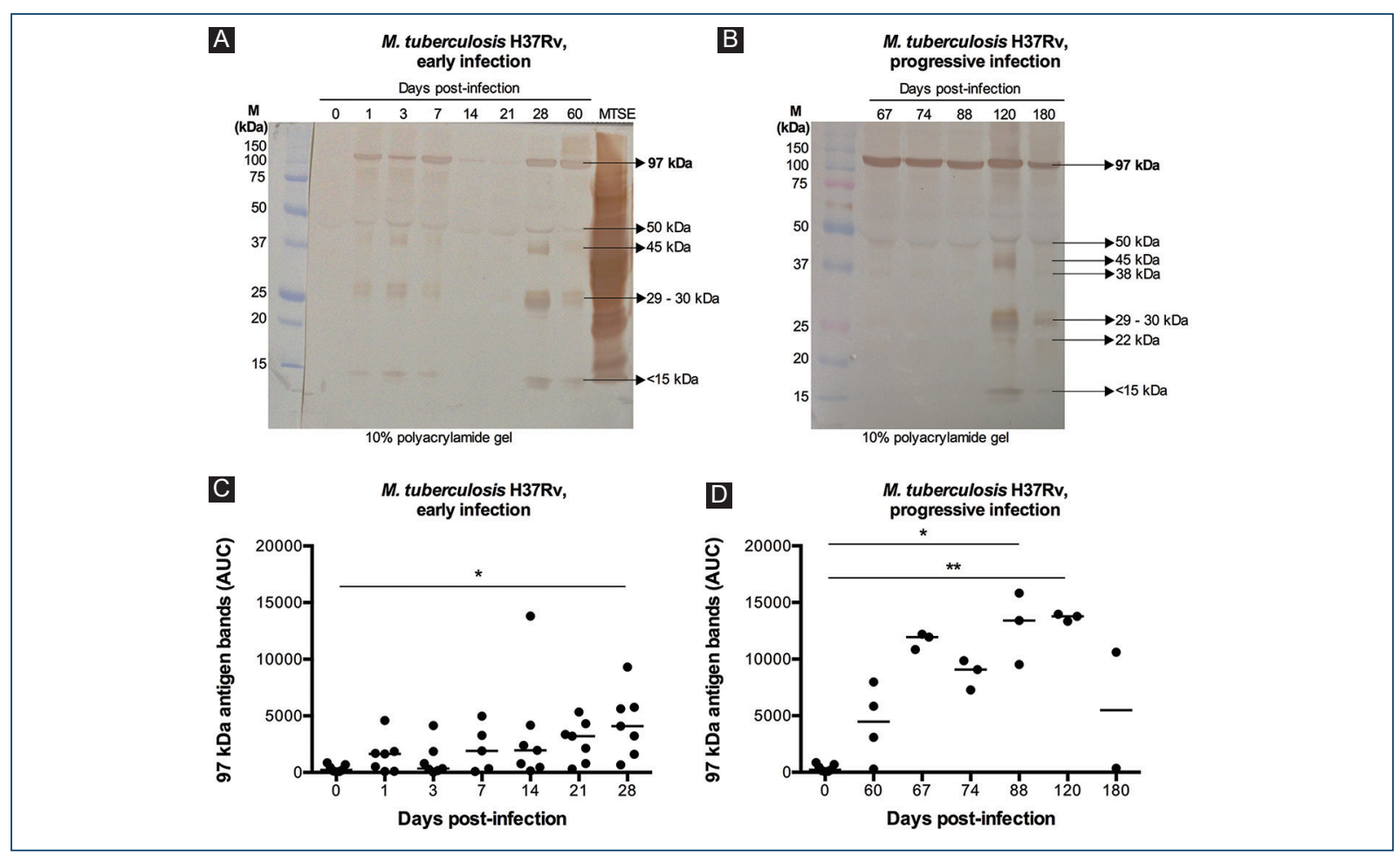

Figure 1. Mice infected with Mycobacterium tuberculosis H37Rv have mycobacterial antigens in their sera. Filtered sera from mice infected with $M$. tuberculosis H37Rv were separated by $3 / 10 \%$ SDS-polyacrylamide gel electrophoresis and then transferred to polyvinylidene fluoride membranes, which were analyzed by Western blot using an anti-M. tuberculosis total extract rabbit serum as primary antibody. A-C: early infection (days 0-28 post-infection). The graph in C represents the area under the curve (AUC) of $97 \mathrm{kDa}$ antigen bands from 5 to $7 \mathrm{mice} /$ day. B-D: progressive infection (days 60-180 post-infection). The graph in D represents the AUC of $97 \mathrm{kDa}$ antigen bands from 2 to 7 mice/day. Data were analyzed with Kruskal-Wallis test followed by Dunn's multiple comparisons test $\left({ }^{*} p>0.05\right)$. M, molecular mass standard. MTSE, M. tuberculosis soluble extract.

antibody (Fig. 2B), which confirms that this method specifically detects mycobacterial antigens.

In days 67-180 post-infection, mice infected with M. tuberculosis H37Rv and treated with isoniazid, rifampicin, and pyrazinamide showed a marked decrease in circulating mycobacterial antigens (Fig. 3A and $\mathrm{C}$ ). In contrast, mice infected with MDR M. tuberculosis CIBIN99 showed no decrease in the concentration of circulating mycobacterial antigens (Fig. 3B and D); the AUC of the $97 \mathrm{kDa}$ antigen in the sera of mice infected with $M$. tuberculosis CIBIN99 was significantly higher than the AUC of the $97 \mathrm{kDa}$ antigen in the sera of mice infected with $M$. tuberculosis H37Rv on day 74 post-infection (Fig. 3C and D).

To evaluate if intratracheal infection with other mycobacteria of $M$. tuberculosis complex also led to the presence of mycobacterial antigens in circulation, we analyzed the sera of mice infected with $M$. bovis AN5 strain (virulent) or 534 strain (avirulent). Circulating mycobacterial antigens, including a prominent band of $97 \mathrm{kDa}$, were found on days 14 and 21 post-infection in the sera of mice infected with the AN5 strain (Fig. 4A and C), while the sera of mice infected with the 534 strain contained low amounts of mycobacterial antigens even up to day 120 post-infection, but did not contain the $97 \mathrm{kDa}$ band (Fig. 4B and D).

To determine if the $97 \mathrm{kDa}$ antigen could potentially be used as a diagnostic marker for TB, we analyzed the sera of 19 TB patients with positive baciloscopy and 12 healthy volunteers. The sera of the TB patients contained an antigen of $97 \mathrm{kDa}$, which is in the same position as the antigen found in the sera of mice infected with M. tuberculosis H37Rv (Fig. 5A). The sera of TB patients contained significantly higher concentrations of the $97 \mathrm{kDa}$ antigen than the sera of healthy volunteers (Fig. 5A and $\mathrm{B}$ ); the area under the receiver-operator characteristic curve is 0.75 (0.58-0.92, $p>0.019$ ) and, for an AUC cutoff value of 2336, the 


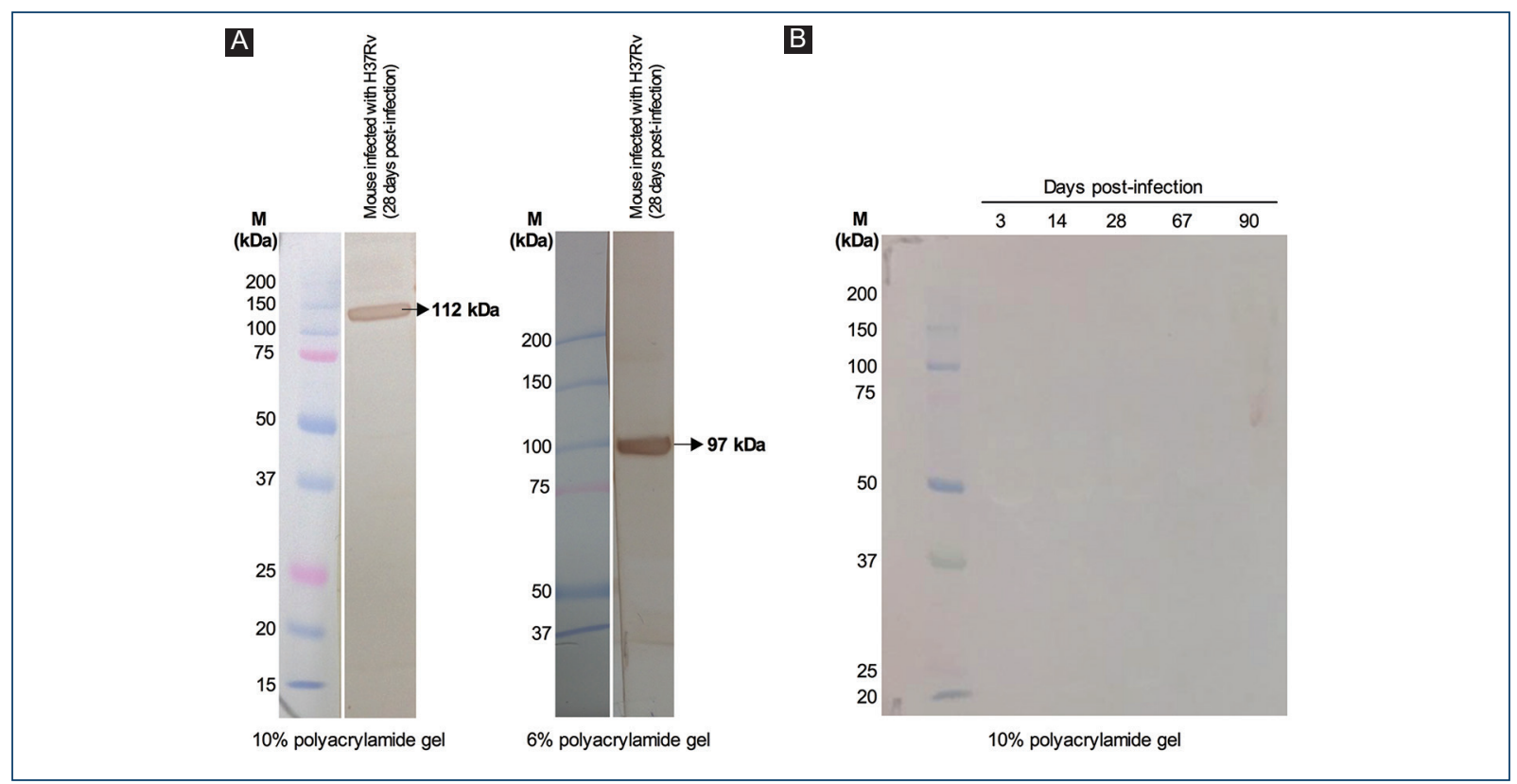

Figure 2. Controls for the Western blot detection of Mycobacterium tuberculosis antigens. A: left panel: filtered sera from a mouse infected with $M$. tuberculosis H37Rv (28 days post-infection) were separated by $3 / 10 \%$ SDS-polyacrylamide gel electrophoresis (PAGE) and then transferred to a polyvinylidene fluoride (PVDF) membrane, which was analyzed by Western blot using an anti-M. tuberculosis total extract rabbit serum as primary antibody. Right panel: filtered sera from a mouse infected with $M$. tuberculosis H37Rv (the same sera that were used in the left panel and in Fig. 4) were separated by $3 / 6 \%$ SDS-PAGE and then transferred to a PVDF membrane, which was analyzed by Western blot using an anti-M. tuberculosis total extract rabbit serum as primary antibody. B: filtered sera from mice infected with $M$. tuberculosis $\mathrm{H} 37 \mathrm{Rv}$ were separated by $3 / 10 \%$ SDS-PAGE and then transferred to a PVDF membrane, which was analyzed by Western blot using the serum of a non-immunized rabbit as primary antibody.

sensitivity is $68 \%(44-87 \%)$ and the specificity is $67 \%$ (35-90\%) (Fig. 5C).

\section{Discussion}

To curb the current TB epidemic ${ }^{10}$, a sensitive, fast, and inexpensive point-of-care TB diagnostic test is necessary, and serological diagnostic methods fulfill these requirements. To develop these methods, it is necessary to identify $M$. tuberculosis antigens that are found in individuals with active TB, but not in individuals successfully treated with antibiotics or in healthy individuals. To identify such $M$. tuberculosis antigens, we first analyzed the sera of mice infected with $M$. tuberculosis using a Western blot method with a rabbit primary antibody that binds to MTTE antigens. We found that infected mice had mycobacterial antigens in their sera from the $1^{\text {st }}$ day after infection, with a predominance of a $97 \mathrm{kDa}$ antigen; antigen concentrations remained constant up to 180 days post-infection.
The mouse model of pulmonary TB that we used in this study is well characterized. Histopathological studies of these mice clearly define two phases of the disease: an acute phase and a progressive phase. The acute phase lasts from days 1 to 28 post-infection and is characterized by the development of an inflammatory infiltrate in the alveolar-capillary interstitium (days 1-7) and by the formation of granulomas (from day 14 onward). The progressive phase, from day 60 onward, is characterized by progressive pneumonia, with proteinaceous deposits in the alveolar space and focal necrosis ${ }^{12}$. Without treatment, $80-90 \%$ of mice die as a consequence of the infection, showing pneumonic areas in $75-80 \%$ of the lung ${ }^{12}$. Antibiotic treatment decreases lung parenchyma damage and increases the survival of mice infected with antibiotic-susceptible M. tuberculosis strains ${ }^{13}$. We report here for the $1^{\text {st }}$ time that mice health improvement after successful antibiotic treatment is associated with a marked decrease in circulating mycobacterial antigens; moreover, when mice 


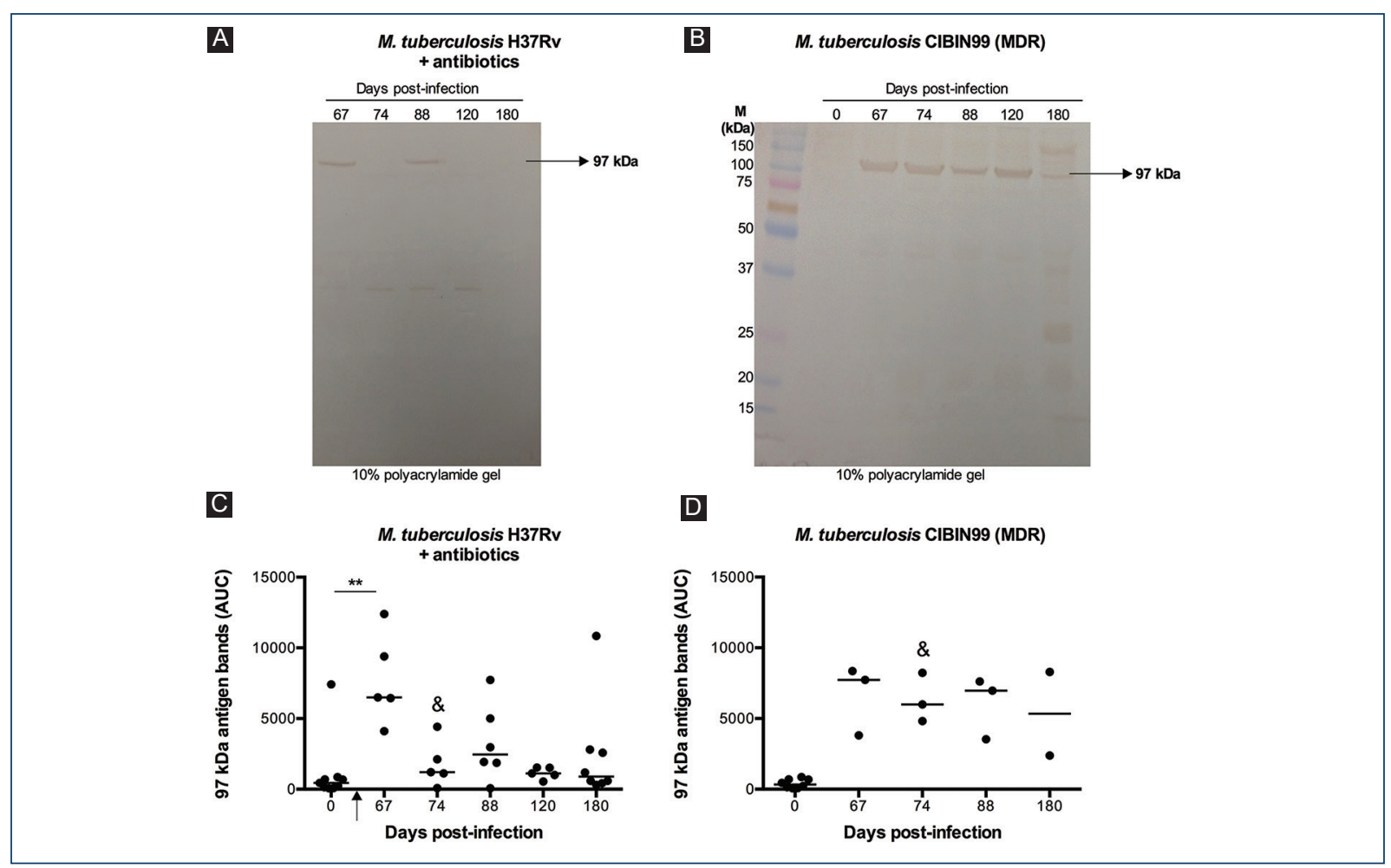

Figure 3. Treatment with isoniazid, rifampicin, and pyrazinamide decreases circulating mycobacterial antigens. A-C: filtered sera from mice infected with antibiotic-susceptible Mycobacterium tuberculosis H37Rv; B-D: filtered with multidrug-resistant $M$. tuberculosis CIBIN99, were separated by 3/10\% SDS-polyacrylamide gel electrophoresis and then transferred to polyvinylidene fluoride (PVDF) membranes, which were analyzed by Western blot using an anti-M. tuberculosis total extract rabbit serum as primary antibody. Antibiotic treatment (with isoniazid, rifampicin, and pyrazinamide) was started on day 60 post-infection (vertical arrow) and was administered daily. C-D: the area under the curve (AUC) of $97 \mathrm{kDa}$ antigen bands from 2 to 8 mice/day. Data were analyzed with Kruskal-Wallis test followed by Dunn's multiple comparisons test ( ${ }^{*} p>0.05$ ). Data were also analyzed with Mann-Whitney U-test, to compare the $97 \mathrm{kDa}$ antigen AUC in mice infected with H37Rv with the corresponding AUC in mice infected with CIBIN99 ( $\&, \mathrm{p}<0.05$ between the indicated groups). M, molecular mass standard.

were infected with a MDR $M$. tuberculosis strain, the progressive disease was associated with persistence of circulating mycobacterial antigens. These results open the possibility of studying these antigens as potential biomarkers for monitoring disease progression and response to antibiotic treatment.

The previous studies have identified $M$. tuberculosis antigens in the sera of TB patients, including ESAT-6 (Rv3875, $9.9 \mathrm{kDa})^{14}$, CFP-10 (Rv3874, $\left.10.8 \mathrm{kDa}\right)^{14}$, alpha-crystallin protein (Rv2031c, $16.2 \mathrm{kDa})^{15,16}$, MPT32 (Rv1860, $32.7 \mathrm{kDa})^{17}$, MPT64 (Rv1980c, $\left.24.9 \mathrm{kDa}\right)^{18}$, mycothiol acetyltransferase (Rv0819, $33.6 \mathrm{kDa})^{19}$, the antigen 85 complex (Rv3804c, Rv1886c, and Rv0129c; $35.7,34.6$, and $36.8 \mathrm{kDa})^{20}$, and heat-shock protein 65 $(\mathrm{Rv} 0440,56.7 \mathrm{kDa})^{21}$. The main antigens that we identified in the sera of infected mice have molecular masses of $<15 \mathrm{kDa}$ (which could correspond to ESAT-6 and/or CFP-10), 29-30 kDa (which could correspond to proteins from the antigen 85 complex) $)^{20,22}, 45 \mathrm{kDa}$ (which could correspond to trehalose-6-phosphate phosphatase, Rv3372, $41.7 \mathrm{kDa}$ ), $50 \mathrm{kDa}$, and $97 \mathrm{kDa}$. Shende et al. separated sera from three active TB patients by SDS-PAGE and analyzed them by Western blot with a goat IgG antibody raised against a $M$. tuberculosis avirulent strain H37Ra sonicate; they found that this antibody binds to circulating mycobacterial antigens of $16,20,43,55,85,140$, and $170 \mathrm{kDa}^{23}$. This pattern is similar, although not identical, to the pattern of circulating mycobacterial antigens that we report in this study; the differences could be explained by the different mycobacteria strain used to raise the primary antibodies (H37Ra vs. H37Rv) and by the hosts of these primary antibodies (goat vs. rabbit).

The $97 \mathrm{kDa}$ antigen is a mycobacteria-specific antigen since it is detected by the serum from rabbits immunized with MTTE, but not by the serum from a 


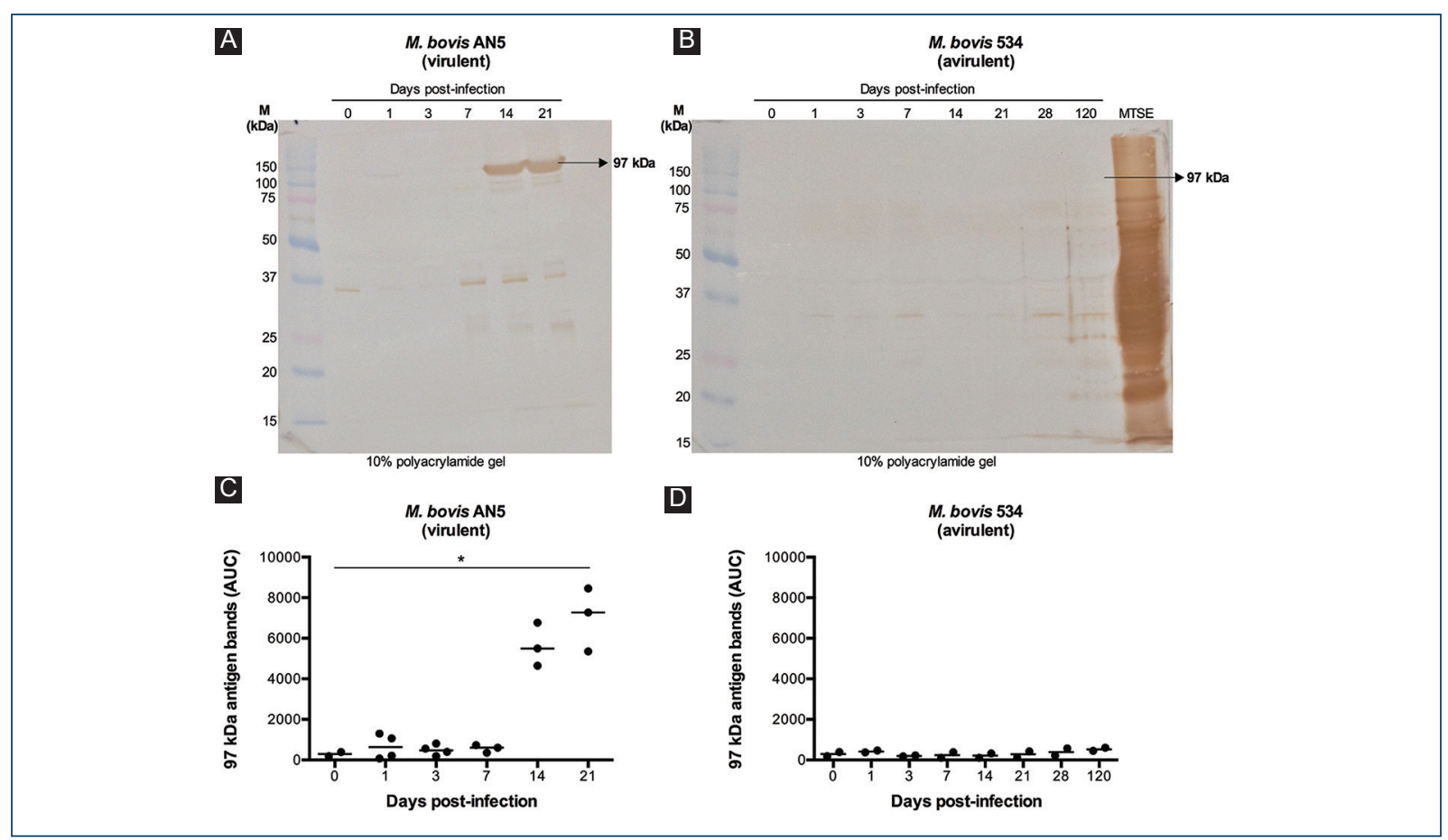

Figure 4. Mice infected with virulent Mycobacterium bovis AN5, but not with avirulent $M$. bovis 534 , present a $97 \mathrm{kDa}$ antigen in their sera. A-C: filtered sera from mice infected with virulent M. bovis AN5 (days 0-21 post-infection), B-D: filtered with avirulent $M$. bovis 534 (days 0-120 post-infection), were separated by $3 / 10 \%$ SDS-polyacrylamide gel electrophoresis and then transferred to polyvinylidene fluoride membranes, which were analyzed by Western blot using an anti-Mycobacterium tuberculosis total extract rabbit serum as primary antibody. C-D: the area under the curve (AUC) of $97 \mathrm{kDa}$ antigen bands from 2 to 4 mice/day. Data were analyzed with Kruskal-Wallis test followed by Dunn's multiple comparisons test (*p > 0.05). AUC, area under the curve. M, molecular mass standard. MTSE, M. tuberculosis soluble extract.

non-immunized rabbit. We propose the $97 \mathrm{kDa}$ antigen as a virulence-specific antigen related to M. tuberculosis complex infection since this protein is detected in the sera of mice infected with either $M$. tuberculosis H37Rv or a virulent $M$. bovis strain, but not in the sera of mice infected with an avirulent $M$. bovis strain. Moreover, the $97 \mathrm{kDa}$ antigen is increased in the sera of patients with active pulmonary TB, compared to healthy volunteers. The $97 \mathrm{kDa}$ was present in the sera of some healthy volunteers, which may reflect a latent or a subclinical infection with $M$. tuberculosis, but the detection of the $97 \mathrm{kDa}$ antigen still had a sensitivity of $68 \%$ and a specificity of $67 \%$ for the identification of active TB. M. tuberculosis H37Rv (ATCC 25618) proteome ${ }^{24}$ reports four proteins with a molecular mass (as calculated from the full precursor canonical sequence) close to 97 kDa: DNA polymerase I (Rv1629, 98.5 kDa), PPE family protein PPE35 (Rv1918c, $97.9 \mathrm{kDa}$ ), alanine-tRNA ligase (Rv2555c, $97.4 \mathrm{kDa}$ ), and replicative DNA helicase (Rv0058, $96.9 \mathrm{kDa}$ ). Sequencing of the $97 \mathrm{kDa}$ antigen is required to confirm its identity.
The presence of intracellular M. tuberculosis antigens in the blood of infected individuals could be explained by whole mycobacteria that reach the bloodstream while disseminating from granulomas ${ }^{25}$. We observed no significant differences in the antigens detected in unfiltered sera or in sera filtered through a $0.45 \mu \mathrm{m}$ pore size membrane, so the antigens that we detected were not part of whole mycobacteria. In this mouse model of TB, live M. tuberculosis can be found in the circulation from the $1^{\text {st }}$ day post-infection, and antigens released from these mycobacteria, through the mycobacteria secretion system ${ }^{26}$ or from vesicles released by M. tuberculosis $^{27}$, could explain why mycobacterial antigens were detected in serum for day 1 post-infection. Circulating mycobacterial antigens could also come from dead mycobacteria released from necrotic immune cells or from extracellular vesicles released from infected immune cells s8-30. $^{28}$.

Circulating mycobacterial antigens have been proposed as targets for serological diagnostic methods for $\mathrm{TB}^{14,31,32}$. Our study demonstrates a strategy that can 


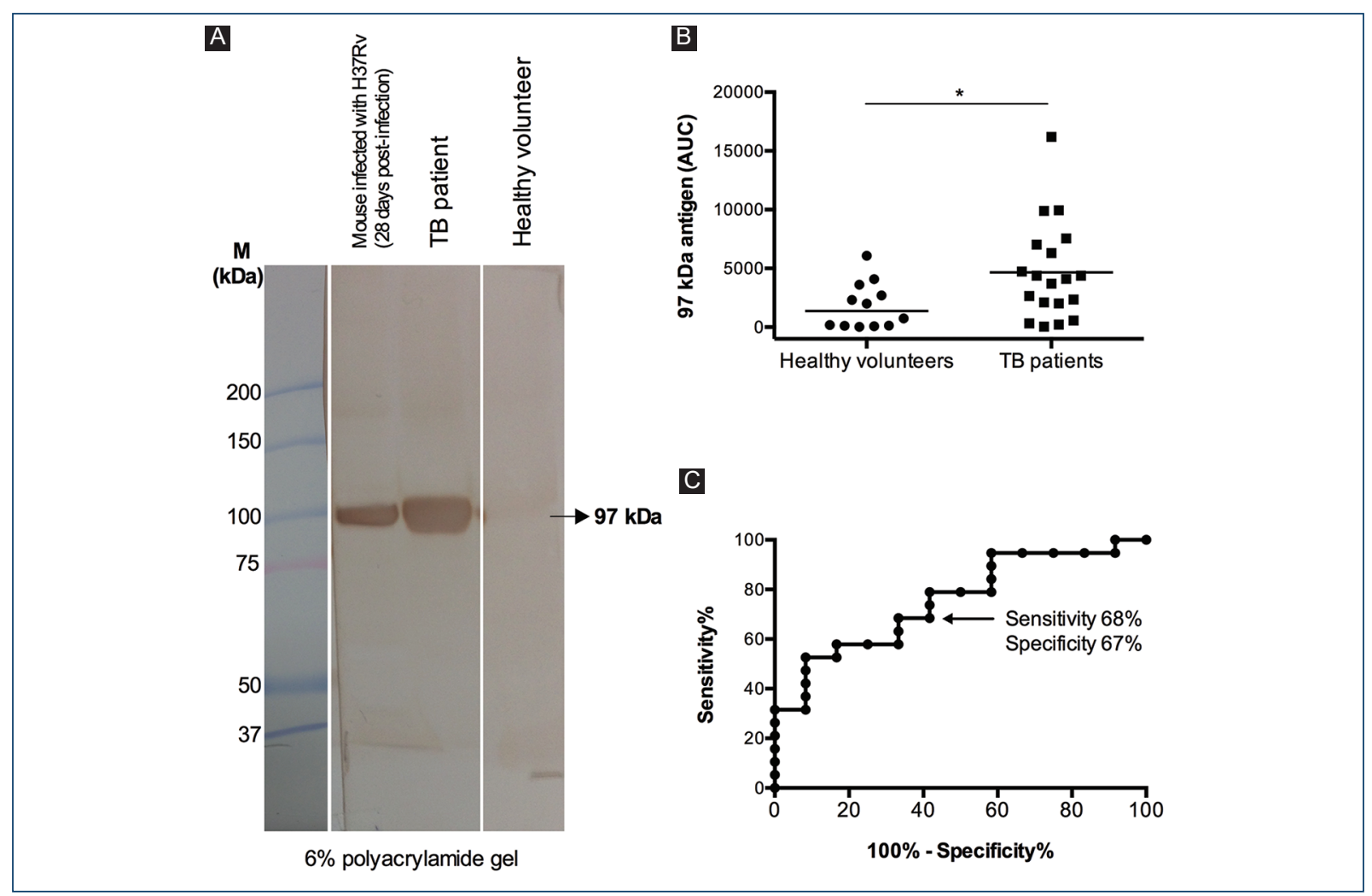

Figure 5. An antigen of $97 \mathrm{kDa}$ is present in the sera of patients with active pulmonary tuberculosis. A: filtered sera from a mouse infected with Mycobacterium tuberculosis H37Rv (28 days post-infection), from a tuberculosis (TB) patient and from a healthy volunteer, were separated by $3 / 6 \%$ SDS-polyacrylamide gel electrophoresis and then transferred to a polyvinylidene fluoride membrane, which was analyzed by Western blot using an anti-M. tuberculosis total extract rabbit serum as primary antibody. B: area under the curve (AUC) of the $97 \mathrm{kDa}$ antigen in the sera of 19 TB patients and 12 healthy volunteers. Data were analyzed with Mann-Whitney U-test $\left({ }^{*} p<0.05\right)$. C: receiver-operator characteristic curve of the data in C. AUC, area under the curve. M, molecular mass standard.

be used to identify additional targets for these serological diagnostic methods; in particular, we report a $97 \mathrm{kDa}$ antigen that identifies patients with active pulmonary TB with $68 \%$ sensitivity and $67 \%$ specificity. The sensitivity and specificity could be increased using a combination of antigens or by analyzing the whole pattern of circulating mycobacterial antigens that are present in the patient sera.

\section{Conclusion}

We report a method that can be used to detect circulating mycobacterial antigens and identified a novel 97 $\mathrm{kDa}$ antigen in the sera of mice infected with M. tuberculosis and of patients with active pulmonary TB. The presence of the $97 \mathrm{kDa}$ antigen in mice sera correlated with lung infection with $M$. tuberculosis H37Rv or with virulent $M$. bovis, and this antigen decreased after successful antibiotic treatment. The $97 \mathrm{kDa}$ antigen could be used as a target, alone or in combination with other antigens, in serological diagnostic methods for TB.

\section{Acknowledgments}

Funding was provided by Consejo Nacional de Ciencia y Tecnología (CONACYT grant 221002 to Dr. Estrada-García) and by Secretaría de Investigación y Posgrado (SIP), Instituto Politécnico Nacional (IPN). Dr. Ruiz-Sánchez and Dr. Francisco-Cruz were recipients of CONACYT fellowships. Dr. Serafín-López, Dr. Chacón-Salinas, and Dr. Estrada-García are fellows of Comisión de Operación y Fomento de Actividades Académicas (COFAA)-IPN. Dr. Serafín-López, Dr. Chacón-Salinas, Dr. Estrada-García, and Dr. Wong-Baeza are fellows of Estímulo al Desempeño de los Investigadores (EDI)-IPN. This work was partially carried out with equipment of "Laboratorio Nacional para Servicios Especializados de Investigación, Desarrollo e Innovación $(l+D+i)$ para Farmoquímicos y Biotecnológicos" 
(LANSEIDI-FarBiotec-CONACYT), which is part of Unidad de Desarrollo e Investigación en Bioprocesos. (UDIBI)-Instituto Politécnico Nacional (IPN).

\section{Conflicts of interest}

The authors declare that they have no conflicts of interest.

\section{Ethical disclosures}

Protection of human and animal subjects. The authors declare that the procedures followed were in accordance with the regulations of the relevant clinical research ethics committee and with those of the Code of Ethics of the World Medical Association (Declaration of Helsinki).

Confidentiality of data. The authors declare that they have followed the protocols of their work center on the publication of patient data.

Right to privacy and informed consent. The authors have obtained the written informed consent of the patients or subjects mentioned in the article. The corresponding author is in possession of this document.

\section{References}

1. Global Tuberculosis Report 2017. Geneva: World Health Organization; 2017.

2. Centro Nacional de Programas Preventivos y Control de Enfermedades (CENAPRECE), Secretaría de Salud, México. Available from: http://www. cenaprece.salud.gob.mx/programas/interior/micobacteriosis/tuberculosis/ cifras_oficiales.html.

3. World Health Organization. Tuberculosis Profile in Mexico; 2018. Available from: http://www.who.int/tb/data.

4. Cadena AM, Fortune SM, Flynn JL. Heterogeneity in tuberculosis. Nat Rev Immunol. 2017;17:691-702.

5. Vordermeier HM, Venkataprasad N, Harris DP, Ivanyi J. Increase of tuberculous infection in the organs of $B$ cell-deficient mice. Clin Exp Immunol. 1996;106:312-6.

6. Maglione PJ, Xu J, Chan J. B cells moderate inflammatory progression and enhance bacterial containment upon pulmonary challenge with $\mathrm{My}$ cobacterium tuberculosis. J Immunol. 2007;178:7222-34.

7. Guirado E, Amat I, Gil O, Diaz J, Arcos V, Caceres N, et al. Passive serum therapy with polyclonal antibodies against Mycobacterium tuberculosis protects against post-chemotherapy relapse of tuberculosis infection in SCID mice. Microbes Infect. 2006;8:1252-9.

8. Lopez Y, Yero D, Falero-Diaz G, Olivares N, Sarmiento ME, Sifontes S, et al. Induction of a protective response with an IgA monoclonal antibody against Mycobacterium tuberculosis $16 \mathrm{kDa}$ protein in a model of progressive pulmonary infection. Int J Med Microbiol. 2009;299:447-52.

9. Hamasur B, Haile M, Pawlowski A, Schroder U, Kallenius G, Svenson SB. A mycobacterial lipoarabinomannan specific monoclonal antibody and its $\mathrm{F}(\mathrm{ab}$ ') fragment prolong survival of mice infected with Mycobacterium tuberculosis. Clin Exp Immunol. 2004:138:30-8.

10. Young DB, Perkins MD, Duncan K, Barry CE $3^{\text {rd }}$. Confronting the scientific obstacles to global control of tuberculosis. J Clin Invest. 2008;118:1255-65.

11. Grange JM, Laszlo A. Serodiagnostic tests for tuberculosis: a need for assessment of their operational predictive accuracy and acceptability. Bull World Health Organ. 1990;68:571-6.
12. Hernandez-Pando $R$, Orozcoe $H$, Sampieri A, Pavon $L$, Velasquillo $C$, Larriva-Sahd J, et al. Correlation between the kinetics of Th1, Th2 cells and pathology in a murine model of experimental pulmonary tuberculosis. Immunology. 1996;89:26-33.

13. Fabre RA, Perez TM, Aguilar LD, Rangel MJ, Estrada-Garcia I, Hernandez-Pando R, et al. Transfer factors as immunotherapy and supplement of chemotherapy in experimental pulmonary tuberculosis. Clin Exp Immunol. 2004;136:215-23.

14. Liu C, Zhao Z, Fan J, Lyon CJ, Wu HJ, Nedelkov D, et al. Quantification of circulating Mycobacterium tuberculosis antigen peptides allows rapid diagnosis of active disease and treatment monitoring. Proc Natl Acad Sci U S A. 2017;114:3969-74.

15. Raja A, Devi KR, Ramalingam B, Brennan PJ. Immunoglobulin G, A, and $M$ responses in serum and circulating immune complexes elicited by the 16-kilodalton antigen of Mycobacterium tuberculosis. Clin Diagn Lab Immunol. 2002;9:308-12.

16. Kaushik A, Singh UB, Porwal C, Venugopal SJ, Mohan A, Krishnan A, et al. Diagnostic potential of $16 \mathrm{kDa}(\mathrm{HspX}$, alpha-crystalline) antigen for serodiagnosis of tuberculosis. Indian J Med Res. 2012;135:771-7.

17. Tucci P, Gonzalez-Sapienza G, Marin M. Pathogen-derived biomarkers for active tuberculosis diagnosis. Front Microbiol. 2014:5:549.

18. Bai L, Chen Y, Bai Y, Chen Y, Zhou J, Huang A. Fullerene-doped polyaniline as new redox nanoprobe and catalyst in electrochemical aptasensor for ultrasensitive detection of Mycobacterium tuberculosis MPT64 antigen in human serum. Biomaterials. 2017;133:11-9.

19. Zeitoun H, Bahey-El-Din M, Kassem MA, Aboushleib HM. Mycothiol acetyltransferase (Rv0819) of Mycobacterium tuberculosis is a potential biomarker for direct diagnosis of tuberculosis using patient serum specimens. Lett Appl Microbiol. 2017;65:504-11.

20. Landowski CP, Godfrey HP, Bentley-Hibbert SI, Liu X, Huang Z, Sepulveda $\mathrm{R}$, et al. Combinatorial use of antibodies to secreted mycobacterial proteins in a host immune system-independent test for tuberculosis. J Clin Microbiol. 2001;39(7):2418-24.

21. Flores LL, Steingart KR, Dendukuri N, Schiller I, Minion J, Pai M, et al. Systematic review and meta-analysis of antigen detection tests for the diagnosis of tuberculosis. Clin Vaccine Immunol. 2011;18:1616-27.

22. Bentley-Hibbert SI, Quan X, Newman T, Huygen K, Godfrey HP. Pathophysiology of antigen 85 in patients with active tuberculosis: antigen 85 circulates as complexes with fibronectin and immunoglobulin G. Infect Immun. 1999;67:581-8.

23. Shende N, Gupta S, Upadhye V, Kumar S, Harinath BC. Isolation and analysis of circulating tuberculous antigens in Mycobacterium tuberculosis. Indian J Tuberc. 2007;54:125-9.

24. UniProt C. UniProt: a hub for protein information. Nucleic Acids Res. 2015;43:D204-12.

25. O'Garra A, Redford PS, McNab FW, Bloom Cl, Wilkinson RJ, Berry MP. The immune response in tuberculosis. Annu Rev Immunol. 2013;31:475527.

26. Forrellad MA, Klepp LI, Gioffre A, Sabio y Garcia J, Morbidoni HR, de la Paz Santangelo M, et al. Virulence factors of the Mycobacterium tuberculosis complex. Virulence. 2013;4:3-66.

27. Prados-Rosales R, Baena A, Martinez LR, Luque-Garcia J, Kalscheuer R, Veeraraghavan $\mathrm{U}$, et al. Mycobacteria release active membrane vesicles that modulate immune responses in a TLR2-dependent manner in mice. $\mathrm{J}$ Clin Invest. 2011;121:1471-83.

28. Ramachandra L, Qu Y, Wang Y, Lewis CJ, Cobb BA, Takatsu K, et al. Mycobacterium tuberculosis synergizes with ATP to induce release of microvesicles and exosomes containing major histocompatibility complex class II molecules capable of antigen presentation. Infect Immun. 2010;78:5116-25.

29. Giri PK, Kruh NA, Dobos KM, Schorey JS. Proteomic analysis identifies highly antigenic proteins in exosomes from Mycobacterium tuberculosis-infected and culture filtrate protein-treated macrophages. Proteomics. 2010;10:3190-202

30. Alvarez-Jimenez VD, Leyva-Paredes K, Garcia-Martinez M, Vazquez-Flores L, Garcia-Paredes VG, Campillo-Navarro M, et al. Extracellular vesicles released from Mycobacterium tuberculosis-Infected neutrophils promote macrophage autophagy and decrease intracellular mycobacterial survival. Front Immunol. 2018;9:272.

31. Attallah AM, Malak CA, Ismail H, El-Saggan AH, Omran MM, Tabll AA Rapid and simple detection of a Mycobacterium tuberculosis circulating antigen in serum using dot-ELISA for field diagnosis of pulmonary tuberculosis. J Immunoassay Immunochem. 2003;24:73-87.

32. El-Masry S, El-Kady I, Zaghloul MH, Al-Badrawey MK. Rapid and simple detection of a Mycobacterium circulating antigen in serum of pulmonary tuberculosis patients by using a monoclonal antibody and Fast-Dot-ELISA. Clin Biochem. 2008;41:145-51. 